\title{
Tratamento Preconizado pelo Grupo dos Doutores Graham Hughes e Munther Khamashta na Abordagem de Gestante com Anticorpos Antifosfolípides
}

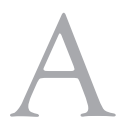

proveitando esta edição especial sobre gestação e doenças reumatológicas, e por já ter tido a oportunidade de, durante quatro anos, como fellow da Lupus Unit do Saint Thomas' Hospital em Londres, vivenciar o manuseio dessa dificil situação clínica, transcrevo abaixo as normas adotadas pela equipe multidisciplinar chefiada pelos Drs. Graham Hughes e Munther Khamashta na abordagem de gestantes com anticorpos antifosfolípides circulantes ou a síndrome do anticorpo antifosfolípideo (SAF).

Muitos dos pacientes com SAF são mulheres em idade fértil, sendo a ocorrência de gestação, portanto, um fato esperado e relativamente freqüente.

O período gestacional em pacientes com SAF constitui causa de apreensão na prática clínica. Principalmente porque não existe consenso sobre a melhor forma de acompanhamento dessas pacientes durante o período gestacional.

Inicialmente, uma história clínica detalhada pode ser de auxílio na determinação dos potenciais riscos da gestação. Dados como número de gestações anteriores, abortamentos, perdas fetais, hipertensão arterial durante a gestação, prematuridade, baixo peso fetal, pré-eclâmpsia materna e fenômenos trombo-embólicos durante a gestação e/ou período pós-natal, podem ser de auxílio no direcionamento terapêutico e na tomada de medidas adicionais.

Mulheres assintomáticas com anticorpos antifosfolípides circulantes: embora não exista consenso sobre a melhor forma de acompanhamento dessas pacientes durante o período gestacional, tem-se recomendado a todas as gestantes com anticorpos antifosfolípides circulantes, o uso de aspirina na dose única diária de $75 \mathrm{mg} / \mathrm{dia}^{(1)}$ (no Brasil utilizamos 100mg/ dia, o que corresponde à dose de aspirina infantil).

A presença de anticorpos antifosfolípides representa importante risco de perda fetal, retardo de crescimento intra-uterino e desenvolvimento de pré-eclâmpsia, além de potencializar o risco de trombose inerente ao estado gestacional ${ }^{(2,3)}$. Lembramos, porém, que anticorpos anticardiolipina positivos em baixos títulos podem ser encontrados em cerca de $2 \%$ da população obstétrica normal, e tal achado não está associado necessariamente a efeitos deletérios maternos ou fetais.

\begin{abstract}
Mulheres com antecedentes prévios de abortamento de repetição somente no primeiro trimestre: às pacientes que não preencham estritamente o critério de abortamento de repetição (três ou mais perdas consecutivas de primeiro trimestre), como no caso anterior, se prescreve aspirina em baixa dose isoladamente.

No caso de a gestante apresentar antecedentes de abortamento mesmo em uso de aspirina infantil, então lhe é oferecida a opção do uso de aspirina associado a heparina de baixo peso molecular na dose de 5.000 unidades, por via subcutânea, diariamente, a partir do teste de gravidez positivo, até pelo menos o final do primeiro trimestre. Em estudo realizado por este grupo pôde-se comprovar melhora do prognóstico gestacional de $19 \%$ para $70 \%$ após o tratamento com baixas doses de aspirina de todas as gestantes com síndrome antifosfolípide e heparina subcutânea naquelas com antecedente prévio de trombose ${ }^{(1)}$.
\end{abstract}

Mulheres com antecedentes prévios de perda fetal de segundo ou terceiro trimestre, ou gestações com evolução adversa: entende-se como gestação de evolução adversa, prematuridade fetal (<34 semanas por pré-eclâmpsia), pré-eclâmpsia, crescimento intra-uterino restrito ou ruptura prematura de membrana, na presença de anticorpos antifosfolípides. A essas gestantes é oferecida aspirina na dose padrão de $75 \mathrm{mg} /$ dia e 5.000 UI da heparina de baixo peso molecular dalteparina (ou equivalente), subcutânea, uma vez ao dia, durante todo o período gestacional ${ }^{(4,5)}$. Ressaltamos a importância de confirmar que as complicações adversas da gestação anterior sejam consistentes com a SAF, evitando-se tratamentos desnecessários.

Mulheres com antecedentes prévios de tromboembolismos: a todas as gestantes com antecedentes prévios de fenômenos tromboembólicos é oferecido o uso de aspirina $75 \mathrm{mg} /$ dia e $5.000 \mathrm{UI}$ de heparina de baixo peso molecular, subcutânea, uma vez ao dia, desde o teste positivo para gravidez até a $16^{\mathrm{a}}$ ou $20^{\mathrm{a}}$ semana de gestação, quando a dose deve ser dobrada para 5.000 UI duas vezes ao dia até o parto.

Para mulheres com acidente vascular cerebral prévio e que apresentem sintomas durante o período em uso de heparina 5.000 UI uma vez ao dia, devem aumentar a dose 
de heparina para 5.000 UI duas vezes ao dia. Se mesmo nessas dosagens não houver desaparecimento dos sintomas, então as pacientes deverão retornar ao uso de dicumarínicos (como, por exemplo, varfarina), durante o segundo trimestre. Durante o uso de varfarina, o INR deve ser meticulosamente medido duas vezes por semana e mantido ao redor de $2,5^{(6)}$. Para mulheres que necessitem do uso de varfarina durante o período gestacional, é essencial o aconselhamento antes da introdução da droga. Temos evitado a exposição de gestantes à varfarina entre a sexta e décima segunda semana gestacional, já que essa droga pode induzir, embora raramente, efeitos deletérios sobre o embrião (hipoplasia nasal e alteração epifisária). Existem também relatos esporádicos de hemorragias e malformações do sistema nervoso central do feto, por uso de varfarina durante o período gestacional. A heparina não atravessa a placenta e não parece causar efeitos adversos sobre o feto. Por outro lado, embora raramente, relata-se que o uso de heparina a longo prazo possa induzir osteoporose $\mathrm{e}^{(5,6)}$.

Lembramos a redução do efeito anticoagulante de varfarina em uso concomitante com a azatioprina e, portanto, a necessidade de doses mais elevadas do anticoagulante oral para a manutenção do INR em níveis adequados em pacientes com síndrome antifosfolípide secundária. Esse fato é particularmente importante e o clínico deve estar alerta para, no caso de diminuição da dose ou retirada da azatioprina, reajustar a dose do varfarina evitando-se assim o risco de hemorragias ${ }^{(7,8)}$.

Medidas terapêuticas durante o parto e puerpério: Nos casos de pacientes em tratamento para trombofilaxia: (somente para pacientes com fenômenos trombóticos prévios e NÃO para pacientes recebendo heparina profilática para perda fetal).

Caso em uso de heparina, a substância deve ser suspensa durante todo o trabalho de parto. Após o parto, e depois da retirada da placenta, a paciente deve receber $5.000 \mathrm{UI}$ de heparina de baixo peso molecular, no subcutâneo e continuar com 5.000 UI, duas vezes ao dia por três dias.

\section{REFERÊNCIAS}

1. Lima F, Khamashta MA, Buchanan NM, Kerslake S, Hunt BJ, Hugles GR: A study of sixty pregnancies in patients with the antiphospholipid syndrome. Clin Exp Rheumatol 14: 131-6, 1996.

2. Lockshin MD, Druzin ML, Goei S, et al: Antibody to cardiolipin as a predictor of fetal distress or death in pregnant patients with systemic lupus erythematosus. N Engl J Med 313: 152-6, 1985.

3. Branch DW, Scott JR, Kochenour NK, Hershgold E: Obstetric complications associated with lupus anticoagulant. N Engl J Med 313: 1322-6, 1985.
Após esse período, passa a receber uma injeção de 5.000 UI por dia durante as próximas seis semanas ou retornar à dose usual de varfarina, quando conveniente.

Lembramos que as pacientes com SAF secundária e em uso de corticosteróides, principalmente se em uso de mais do que 7,5 mg/ dia, há mais de duas semanas, devem receber $100 \mathrm{mg}$ de hidrocortisona por via intramuscular ou endovenosa a cada 6 horas durante o trabalho de parto em substituição aos corticosteróides orais. Após o parto, os corticosteróides orais podem ser reintroduzidos, de preferência na mesma dose anterior.

\section{ALEITAMENTO MATERNO}

Embora exista uma recomendação para que mães em uso de hidroxicloroquina, aspirina e heparina de baixo peso molecular evitem aleitamento, em nossa experiência não temos observado efeitos adversos dessas drogas nos lactentes amamentados no peito, cujas mães façam uso delas, nas doses rotineiramente utilizadas.

Às mães em uso de varfarina, recomendamos que se verifique se a ingestão de vitamina $\mathrm{K}$ é adequada.

Não recomendamos o aleitamento materno nos casos de pacientes em uso de altas doses de corticosteróides (máximo $40 \mathrm{mg} / \mathrm{dia}$ ). Caso se planeje, porém, diminuir paulatinamente a dose de corticosteróides, pode-se, alternativamente, orientar a mãe para a retirada regular do leite materno, para que o aleitamento no peito possa ser iniciado, quando a dose de corticosteróide materno for adequada.

A azatioprina é excretada no leite materno e, portanto, existe o risco de imunossupressão do recém-nascido. Nossas pacientes, dessa forma, são orientadas a evitar a amamentação. O uso de ciclofosfamida é contra-indicação absoluta à amamentação.

LAIS V. LAGE

Professora Associada e Assistente-doutora do Serviço de Reumatologia da Faculdade de Medicina da Universidade de São Paulo (FMUSP)

4. Nelson-Piercy C: Low molecular weight heparin for obstetric thromboprophylaxis. Br J Obstet Gynaecol 101: 6-8, 1994.

5. Hunt BJ, Doughty HA, Majumdar G, et al: Thromboprophylaxis with low molecular weight heparin (Fragmin) in high risk pregnancies. Thromb Haemost 77: 39-43, 1997.

6. Khamashta MA, Cuadrado MJ, Mujic F, Taub NA, Hunt BJ, Hughes GR: The management of thrombosis in the antiphospholipidantibody syndrome. N Engl J Med 332: 993-7, 1995.

7. Singleton JD, Conyers L: Warfarin and azathioprine: an important drug interaction. Am J Med 92: 217, 1992.

8. Rivier G, Khamashta MA, Hughes GRV: Warfarin and azathioprine: a drug interaction does exist. Am J Med 95: 342, 1993. 